ACCEPTED MANUSCRIPT

\title{
Optical characterization of a novel miniature microwave ICP plasma source in nitrogen flow
}

To cite this article before publication: Ilija Stefanovic et al 2018 Plasma Sources Sci. Technol. in press https://doi.org/10.1088/1361-6595/aaefcc

\section{Manuscript version: Accepted Manuscript}

Accepted Manuscript is "the version of the article accepted for publication including all changes made as a result of the peer review process, and which may also include the addition to the article by IOP Publishing of a header, an article ID, a cover sheet and/or an 'Accepted

Manuscript' watermark, but excluding any other editing, typesetting or other changes made by IOP Publishing and/or its licensors"

This Accepted Manuscript is @ 2018 IOP Publishing Ltd.

During the embargo period (the 12 month period from the publication of the Version of Record of this article), the Accepted Manuscript is fully protected by copyright and cannot be reused or reposted elsewhere.

As the Version of Record of this article is going to be / has been published on a subscription basis, this Accepted Manuscript is available for reuse under a CC BY-NC-ND 3.0 licence after the 12 month embargo period.

After the embargo period, everyone is permitted to use copy and redistribute this article for non-commercial purposes only, provided that they adhere to all the terms of the licence https://creativecommons.org/licences/by-nc-nd/3.0

Although reasonable endeavours have been taken to obtain all necessary permissions from third parties to include their copyrighted content within this article, their full citation and copyright line may not be present in this Accepted Manuscript version. Before using any content from this article, please refer to the Version of Record on IOPscience once published for full citation and copyright details, as permissions will likely be required. All third party content is fully copyright protected, unless specifically stated otherwise in the figure caption in the Version of Record.

View the article online for updates and enhancements. 


\title{
Optical Characterization of a Novel Miniature Microwave ICP Plasma Source in Nitrogen Flow
}

\author{
Ilija Stefanovići ${ }^{1,4}$, Nikita Bibinov ${ }^{1}$, Horia- Eugen Porteanu ${ }^{2}$, Michael Klute ${ }^{3}$, Ralf- \\ Peter Brinkmann ${ }^{3}$ and Peter Awakovicz ${ }^{1}$
}

${ }^{1}$ Ruhr-Universität Bochum, Faculty of Electrical Engineering and Information Technology, Institute for Electrical Engineering and Plasma Technology, Bochum, Germany

${ }^{2}$ Microwave Department, Ferdinand-Braun-Institut, Leibniz-Institut für Höchstfrequenztechnik, Berlin, Germany

${ }^{3}$ Ruhr-Universität Bochum, Faculty of Electrical Engineering and Information Technology, Institute for Theoretical Electrical Engineering, Germany

${ }^{4}$ Serbian Academy of Sciences and Arts, Institute of Technical Sciences, Belgrade, Serbia

E-mail: ilija.stefanovic@rub.de

Received xxxxxx

Accepted for publication $\mathrm{xxxxxx}$

Published xxxxxx

\section{Abstract}

A Miniature Microwave (MMW) Inductively Coupled Plasma Source (ICP) is characterized by optical emission spectroscopy and by optical imaging of nitrogen plasma. The MWW source operates in two different modes $(\mathrm{H}$ - mode and hybrid - $\mathrm{E} / \mathrm{H}$ mode) with different plasma parameters and different emission morphologies, depending on the absorbed microwave $(\mathrm{MW})$ power $\left(P_{a b s}\right)$. The measured spectra of the second positive system $\left(\mathrm{N}_{2}(\mathrm{C}-\right.$ B)) and of the first negative system $\left(\mathrm{N}_{2}{ }^{+}(\mathrm{B}-\mathrm{X})\right)$ of nitrogen reveal an electron density $n_{e}=$ $(6.4 \pm 1.7) \times 10^{18} \mathrm{~m}^{-3}$ and a gas temperature of $T_{g}=(650 \pm 20) \mathrm{K}$ for $P_{a b s}=13 \mathrm{~W}$ at a pressure of $1000 \mathrm{~Pa}$. By increasing the absorbed power to $P_{a b s}=78 \mathrm{~W}$ the parameters increase to $n_{e}=$ $(3.5 \pm 1.7) \times 10^{19} \mathrm{~m}^{-3}$ and $T_{g}=(1600 \pm 100) \mathrm{K}$. The discharge morphology in hybrid and $\mathrm{H}$ mode is different. While in the $\mathrm{H}$-mode the plasma resembles a "donuts" shape, the hybrid mode has a very narrow shape close to the walls and to the gap capacitor of the resonator. For our discharge conditions the power absorption is limited to $158 \mathrm{~W}$, above which the discharge spontaneously switches from $\mathrm{H}$ - mode to hybrid mode.

Keywords: Microwave plasma, inductively coupled plasma, E- mode, H-mode, nitrogen plasma

Owing to achievable high efficiency of power coupling between generator and plasma and due to very broad possible variations of working gas pressure and input energy, a nonequilibrium microwave discharge is very promising for different applications like surface modification of polymers [1], gas conversion [2], cutting and welding [3], analytical spectroscopy [4] etc. The disadvantage of high density microwave plasma is its strong inhomogeneity, mostly because of the limited penetration depth. Therefore, the treatment of broad surfaces with atomic or other chemical active radical flows can be difficult. To solve this problem, the treated surface must be scanned with a microwave reactor or, alternatively, a microwave micro-reactor array can be applied.

A miniature double microwave plasma jet source, as a prototype for such an array, was developed and analyzed in [5]. It was shown that the double Miniature Microwave (MMW) plasma jet source can be operated with argon and oxygen in both capacitive and inductive coupling modes (E and $\mathrm{H}$ ) under very different conditions. For oxygen in $\mathrm{H}$ mode more than $85 \%$ of incident power is absorbed in plasma. 
In order to compare the experimental and theoreticallyexpected conditions the conductivity was simulated and compared with the measured one using COMSOL Multiphysics simulation software.

In the present paper we characterize the plasma parameters in a single MMW reactor, similar to that studied in [5], by using optical emission spectroscopy (OES) in nitrogen flow. The UV emission spectrum of nitrogen consists of two intensive emission systems with different energetic terms and is very sensitive to the variation of the electron density and of the electron energy distribution function. This makes $\mathrm{N}_{2}$ molecule the most appropriate for spectroscopic plasma characterization. The plasma parameters are determined in both E- and H- modes.

The employed plasma source is a loop gap design resembling that of Piasecki [6]. The shape of the copper resonator surrounding a quartz tube is presented on the bottom of Fig. 1. One end of the quartz tube is connected via flange to a vacuum chamber and the other end to a gas flow controller with a gas flow of $150 \mathrm{sccm}$ of nitrogen (Air Liquide) with purity 5.0. The gas pressure can be varied by regulating the pumping speed of the rotary vane pump but for the results presented here is kept to $1000 \mathrm{~Pa}$. Nevertheless, the ultimate vacuum is of the order of $10^{-2} \mathrm{~Pa}$.

The copper resonator has a $0.5 \mathrm{~mm}$ gap (e) that ensures a capacity leading to a resonance of the source without plasma at $2.6 \mathrm{GHz}$. The length of the resonator in the direction parallel to the optical axis is $8 \mathrm{~mm}$. The MW power source is a KU SG 2.45-250A (Kuhne-Electronic) signal generator delivering up to $250 \mathrm{~W}$. The signal generator has an integrated directional coupler and two power meters, measuring the forwarded and reflected powers. The Labview program sets the frequency and the output intensity of the signal generator and reads the two power meters.

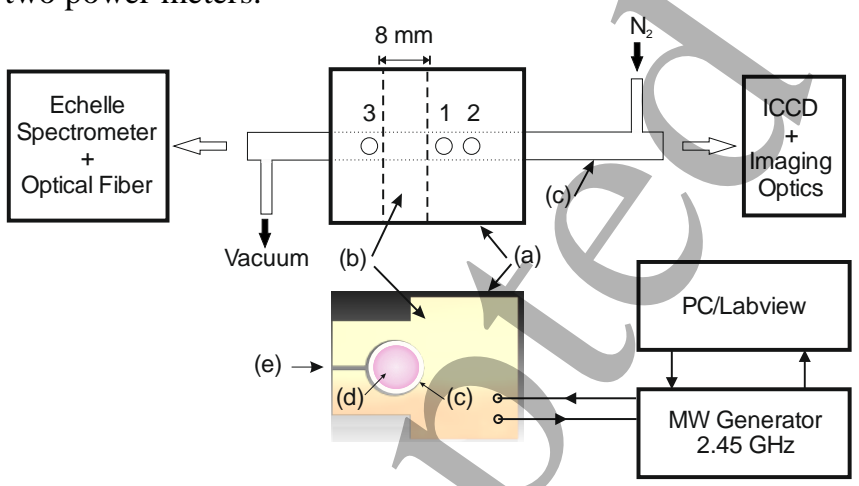

Figure 1. Schematic of the experimental set-up for characterization of MMW plasma source. Top: optical arrangement; bottom: copper resonator cross section perpendicular to the optical axis. (a) $\mathrm{Al}$ shielding, (b) resonator and its position inside the $\mathrm{Al}$ shielding, (c) quartz tube, (d) plasma and (e) gap capacitor.

The top of Fig. 1 shows principle scheme of the optical setup. Microwave plasma is monitored by two optical systems simultaneously. From the left hand side, the echelle spectrometer (ESA 3000, LLA Instruments) is used to measure the spectrum of nitrogen emission, namely of the second positive system $\left(\mathrm{N}_{2}(\mathrm{C}-\mathrm{B})\right)$ and the first negative system $\left(\mathrm{N}_{2}^{+}(\mathrm{B}-\mathrm{X})\right)$. The spectrometer was previously absolutely and relatively calibrated [7]. The spectrometer provides a spectral resolution of $0.015-0.06 \mathrm{~nm}$ in the range of $\lambda=200-800 \mathrm{~nm}$, which suits well for measurements of rotational distributions of $\mathrm{N}_{2}(\mathrm{C}-\mathrm{B})$ and $\mathrm{N}_{2}{ }^{+}(\mathrm{B}-\mathrm{X})$ emission bands. The optical emission is coupled to the spectrometer via optical fiber that collects the light from the plasma through a quartz window.

From the right hand side plasma emission is measured by an intensified charge-coupled device (ICCD) camera through another quartz window. In this way the camera detects the radial emission distribution of the plasma jet. The optical imaging system consists of a macro objective (Rodagon, Rodenstock) with the depth of field around $5 \mathrm{~mm}$ that is focused on plasma resonator's middle plane perpendicular to the discharge axis. In the combination with the UV enhanced ICCD camera (4Picos, Stanford Computer Optics) the radial discharge images have been measured with a spatial resolution of about 28 micrometers. The exposure time of the camera can be varied from a minimum of 200 ps to $1000 \mathrm{~s}$. The chosen exposure time in our experiment is $5 \mathrm{~ms}$ or $20 \mathrm{~ms}$, based on a sufficient measured signal in two different discharge modes.

Because both optical methods record an axially integrated light, in order to get a proper information of plasma parameters in the active region within a resonator cavity, it is necessary to know the axial light distribution, especially in the case when the plasma extends outside the resonator cavity. In addition, to determine the electron density from absolute intensity measurements, the active plasma volume has to be known. In order to measure the axial light distributions, the $\mathrm{Al}$ shielding is provided with three additional holes (1, 2 and 3 on the Fig. 1) having $3 \mathrm{~mm}$ in diameter. By using calibrated echelle spectrometer, it is possible to measure the absolute emission intensities of $\mathrm{N}_{2}(\mathrm{C}, 0-0)$ and $\mathrm{N}_{2}{ }^{+}(\mathrm{B}, 0-0)$ along the discharge axis (i) at $2.5 \mathrm{~mm}$ and $7.5 \mathrm{~mm}$ away from the resonator edge on the right hand side and (ii) $2.5 \mathrm{~mm}$ on the left hand side (Fig. 1). These measurements show that the contribution of plasma outside the resonator cavity to the total line integrated absolute intensity is not higher than $20 \%$. This is latter used as a correction of the OES results.

The gas temperature in the plasma is determined by using the rotational distribution in the emission spectrum of the $\mathrm{N}_{2}$ (C-B,0-0) vibrational band, under the assumption that the translational and rotational degrees of freedom in the ground state of nitrogen molecule $\left(\mathrm{N}_{2}(\mathrm{X})\right)$ are in equilibrium. The electronic impact excitation of diatomic molecules is limited by the selection rule $\Delta \mathrm{J}=0, \pm 1$. Therefore, the rotational distribution in the excited molecular state is approximately equal to the rotational distribution in the ground state of the molecule. Nevertheless, the identification and deconvolution of the measured molecular emission spectra is a complicated 
task that requires high spectral resolution of the spectrometer. To determine rotational temperatures of $\mathrm{N}_{2}(\mathrm{C})$ and $\mathrm{N}_{2}{ }^{+}(\mathrm{B})$ states we use libraries of simulated rotational spectra by different rotational temperatures with the step of $\Delta \mathrm{T}=20 \mathrm{~K}$, which are then convoluted with the instrumental profile of our spectrometer. The measured and tabulated spectra are compared manually until the best match and the interval of confidence are found. The interval of confidence gives an error better than $10 \%$, which provides a good accuracy of OES diagnostics.

Electron density $\left(n_{e}\right)$, reduced electric field $(E / N)$, and gas temperature $\left(T_{g}\right)$ are determined by measuring the molecular nitrogen light emission. This technique has already been used for characterization of different plasma sources containing nitrogen as a working gas [8-10]. Here, only the most important features of the diagnostic will be outlined.

The emission spectrum of nitrogen in the UV range has two distinguished emission systems, namely $\mathrm{N}_{2}(\mathrm{C}-\mathrm{B})$ and $\mathrm{N}_{2}{ }^{+}(\mathrm{B}-$ $\mathrm{X}$ ), whose excited states have very different energetic terms, namely $11.05 \mathrm{eV}$ and $18.74 \mathrm{eV}$, respectively. Therefore, the emission spectrum of nitrogen plasma is very sensitive to variations of the electron energy distribution function. The most relevant collision processes leading to the population of the $\mathrm{N}_{2}(\mathrm{C})$ and $\mathrm{N}_{2}{ }^{+}(\mathrm{B})$ states are

$$
\begin{aligned}
& \mathrm{e}+\mathrm{N}_{2}(\mathrm{X}) \rightarrow \mathrm{N}_{2}(\mathrm{C})+\mathrm{e} \\
& \mathrm{e}+\mathrm{N}_{2}(\mathrm{X}) \rightarrow \mathrm{N}_{2}^{+}(\mathrm{B})+2 \mathrm{e} \\
& \mathrm{e}+\mathrm{N}_{2}{ }^{+}(\mathrm{X}) \rightarrow \mathrm{N}_{2}{ }^{+}(\mathrm{B})+\mathrm{e}
\end{aligned}
$$

Further, the reactions that consider the gain and the loss of metastables $\mathrm{N}_{2}(\mathrm{~A})$ are included in our analysis

$$
\begin{aligned}
& \mathrm{e}+\mathrm{N}_{2}(\mathrm{X}) \rightarrow \mathrm{N}_{2}(\mathrm{~A})+\mathrm{e} \\
& \mathrm{e}+\mathrm{N}_{2}(\mathrm{~A}) \rightarrow \mathrm{N}_{2}(\mathrm{C})+\mathrm{e} \\
& \mathrm{e}+\mathrm{N}_{2}(\mathrm{~A}) \rightarrow \mathrm{N}_{2}(\mathrm{~B})+\mathrm{e} \\
& \mathrm{e}+\mathrm{N}_{2}(\mathrm{~A}) \rightarrow \mathrm{N}_{2}^{+}+2 \mathrm{e} \\
& \mathrm{e}+\mathrm{N}_{2}(\mathrm{~A}) \rightarrow \mathrm{N}+\mathrm{N}+\mathrm{e} \\
& \mathrm{N}_{2}(\mathrm{~A})+\text { wall } \rightarrow \mathrm{N}_{2}(\mathrm{X}) .
\end{aligned}
$$

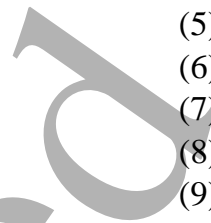

Considering our experimental conditions, $\mathrm{N}_{2}(A)$ metastable pooling and other heavy particle collision reactions of $\mathrm{N}_{2}(\mathrm{~A})$ are neglected.

Under our plasma conditions, the molecular states $\mathrm{N}_{2}(\mathrm{C})$ and $\mathrm{N}_{2}{ }^{+}(\mathrm{B})$ are excited by direct electron impact of nitrogen ground state $\mathrm{N}_{2}(\mathrm{X})$ (Eqs. (1) and (2)) and by stepwise electron impact excitation via the metastable $\mathrm{N}_{2}(\mathrm{~A})$ (Eqs. (5), (6), and (7)) and the ground state of nitrogen ions $\mathrm{N}_{2}{ }^{+}$(X) (Eq. (3)). Cross sections for electron impact excitation of excited states of nitrogen $\left(\sigma_{e x c}\left(E_{k i n}\right)\right)$ are well known [11-13] and are used for the evaluation of $n_{e}$ and $E / N$.

Under given assumptions the intensities of $\mathrm{N}_{2}(\mathrm{C}-\mathrm{B}, 0-0)$ and of $\mathrm{N}_{2}{ }^{+}(\mathrm{B}-\mathrm{X}, 0-0)$ can be described by following equations

$$
\begin{aligned}
I_{N_{2}(C)}= & Q_{N_{2}(C)}\left[N_{2}\right] n_{e}\left(k_{N_{2}(C)}^{N_{2}(X)}+\right. \\
& \left.k_{N_{2}(A)}^{N_{2}(X)} \frac{B 1 \cdot B 2 \cdot k_{N_{2}(C)}^{N_{2}(A)}}{k_{N_{2}(B)}^{N_{2}(A)}+k_{N_{2}(C)}^{N_{2}(A)}+k_{i o n}^{N_{2}(A)}+k_{d i s s}^{N_{2}(A)}+D i f f}\right) \\
I_{N_{2}^{+}(B)}= & Q_{N_{2}^{+}(B)}\left(\left[N_{2}\right] n_{e} k_{N_{2}^{+}(B)}^{N_{2}(X)}+\left[N_{2}^{+}(X)\right] n_{e} k_{N_{2}^{+}(B)}^{N_{2}^{+}(X)}\right)
\end{aligned}
$$

where $\left[\mathrm{N}_{2}\right]$ and $\left[\mathrm{N}_{2}{ }^{+}\right]$are the densities of the respective species and the top and sub-indices at the rate constants $(k)$ represent the molecular states before and after electron impact excitation, respectively. The branching factor $\mathrm{B} 1=0.5$ describes the relative population of the vibrational level v' $=$ 0 of the excitation of $\mathrm{N}_{2}(\mathrm{C})$ by electron impact excitation of $\mathrm{N}_{2}$ (A) estimated in [8]. The branching factor $\mathrm{B} 2=0.5$ represents the Einstein coefficient of the $\mathrm{N}_{2}(\mathrm{C}-\mathrm{B}, 0-0)$ calculated in [14]. The term Diff in Eq. (10) represents the probability of nitrogen metastables' decay by diffusion and quenching on the tube wall and by leaving of the active plasma volume along the tube axis (Eq. I). This term is neglected at the first step of MW plasma characterization. The reliability of this assumption is discussed below. Collisional quenching factors, $Q_{N_{2}(C)}$ and $Q_{N_{2}^{+}(B)}$, are calculated after Eqs. $(12,13)$ by using known Einstein coefficients $\left(A_{N_{2}(C)}, A_{N_{2}^{+}(B)}\right)$ of the respective emission transitions, $\mathrm{N}_{2}(\mathrm{C}-\mathrm{B})$ and $\mathrm{N}_{2}{ }^{+}(\mathrm{B}-\mathrm{X})$, and the rate constants of collisional quenching in nitrogen plasma, $k_{q}^{N_{2}(C)}$ and $k_{q}^{N_{2}^{+}(B)}$ areadopted from [15].

$$
\begin{aligned}
& Q_{N_{2}(C)}=\frac{A_{N_{2}(C)}}{A_{N_{2}(C)}+k_{q}^{N_{2}(C)}\left[N_{2}\right]} \\
& Q_{N_{2}^{+}(B)}=\frac{A_{N_{2}^{+}(B)}}{A_{N_{2}(C)}+k_{q}^{N_{2}^{+}(B)}\left[N_{2}\right]}
\end{aligned}
$$

The rate constants, used in Eqs. $(1,2)$ are calculated by using the known cross sections of electron impact excitations $\left(\sigma_{\text {exc }}\left(E_{k i n}\right)\right)$ [11-13] and the electron velocity distribution function $(\mathrm{EVDF}) f_{v}\left(E_{k i n}\right)$. The EVDFs are determined by solving numerically the Boltzmann equation for different reduced electric field values [16]. The EVDF and the rate constants for electron impact excitations are calculated after Eq. (5), where $E_{k i n}$ is the kinetic energy in $\mathrm{eV}, m_{e}$ the mass and $e$ the elementary charge of an electron.

$$
k_{\text {exc }}=4 \pi \sqrt{2} \int_{0}^{\infty} f_{v}\left(E_{k i n}\right) \sqrt{\frac{2 e}{m_{e}}} E_{k i n} \sigma_{\text {exc }}\left(E_{k i n}\right) d E_{k i n}
$$

The system of equations is closed by the assumption of quasi-neutrality between electrons and molecular ions $\left(\mathrm{N}_{2}{ }^{+}\right.$, $\mathrm{N}_{4}{ }^{+}$). Four atomic ions are produced in nitrogen plasma in three particle reaction of diatomic ions. Under relative low pressure and high gas temperature as those of our experimental conditions, the participation of four atomic nitrogen ions in charged species balance is, however, negligible. Therefore, the plasma parameters in our MW plasma are determined by a system of simplified non-linear equations (Eq. (6-15) and Eq. (7-16)) of $n_{e}$. 


$$
\begin{aligned}
I_{N_{2}(C)}= & Q_{N_{2}(C)}\left[N_{2}\right] n_{e}\left(k_{N_{2}(C)}^{N_{2}(X)}+\right. \\
& \left.k_{N_{2}(A)}^{N_{2}(X)} \frac{\mathrm{B} 1 \mathrm{~B} 2 k_{N_{2}(C)}^{N_{2}(A)}}{k_{N_{2}(B)}^{N_{2}(A)}+k_{N_{2}(C)}^{N_{2}(A)}+k_{i o n}^{N_{2}(A)}+k_{d i s s}^{N_{2}(A)}}\right) \\
I_{N_{2}^{+}(B)}= & Q_{N_{2}^{+}(B)} \cdot\left(\left[N_{2}\right] n_{e} k_{N_{2}^{+}(B)}^{N_{2}(X)}+n_{e}^{2} k_{N_{2}^{+}(B)}^{N_{2}^{+}(X)}\right)
\end{aligned}
$$

This system has two solutions corresponding to two distinguished physical conditions namely: $\mathrm{N}_{2}(\mathrm{C}-\mathrm{B})$ and $\mathrm{N}_{2}{ }^{+}(\mathrm{B}-\mathrm{X})$ emissions can be excited under (i) high electric field and low electron density, or (ii) by low electric field and high electron density. This ambiguity of the OES diagnostic is solved using the rotational distribution in the emission spectra of neutral and ionized nitrogen molecules [17]. As was mentioned above, the population of rotational levels of neutral nitrogen molecules in MW plasma corresponds to the gas temperature. In contrast, $\mathrm{N}_{2}{ }^{+}$ions are accelerated in the electric field of the plasma and the rotational temperature of these ions increases because of collisions with the ambient gas. The rotational temperature of a molecule is not changed by electron impact excitation. Therefore, if the measured rotational temperature of $\mathrm{N}_{2}{ }^{+}(\mathrm{B}-\mathrm{X})$ ions is similar to the rotational temperature of neutral $\mathrm{N}_{2}(\mathrm{C}-\mathrm{B})$ then both species (neutrals and ions) are excited from the ground state of the neutral molecule $\mathrm{N}_{2}(X)$ through "direct" electron impact excitation (Eqs. (1) and (2)). This case corresponds to the (i) high electric field and low electron density [17]. If, however, the rotational temperature of the emission spectrum of ions is higher than the rotational temperature of neutrals, the $\mathrm{N}_{2}{ }^{+}(\mathrm{B})$ state is excited by electron impact from the ground state of the positive ion $\mathrm{N}_{2}^{+}(\mathrm{X})$ (Eq. (3)), which is characteristic for (ii) high electron density and low electric field [18].

We investigate here two characteristic discharge conditions driven by two different powers: (a) low absorbed power $P_{\text {abs }}=$ $12 \mathrm{~W}$ and (b) high absorbed power $P_{\text {abs }}=78 \mathrm{~W}$. These discharge conditions are chosen as an example of different discharge modes of the MW plasma source, which will be discussed. They are also relevant in accordance to the microwave spectroscopy.

In Fig. 2 the measured emission spectra for low and high absorbed power are presented. The measured rotational temperatures of the $\mathrm{N}_{2}{ }^{+}(\mathrm{B}-\mathrm{X}, 0-0)$ vibrational band are higher than the rotational temperatures of the neutral nitrogen in both cases. In accordance with the above discussion, the discharge conditions for both MW powers are such that the $\mathrm{N}_{2}{ }^{+}(\mathrm{B})$ state is excited mainly by the electron impact excitation of $\mathrm{N}_{2}{ }^{+}(\mathrm{X})$ state (Eq. (3)) and the Eq. (16) can be simplified to Eq. (8-17). The nitrogen density under MW plasma conditions is determined using the measured gas temperature and ideal gas law.

$$
I_{N_{2}^{+}(B)}=Q_{N_{2}^{+}(B)} n_{e}^{2} k_{N_{2}^{+}(B)}^{N_{2}^{+}(X)}
$$

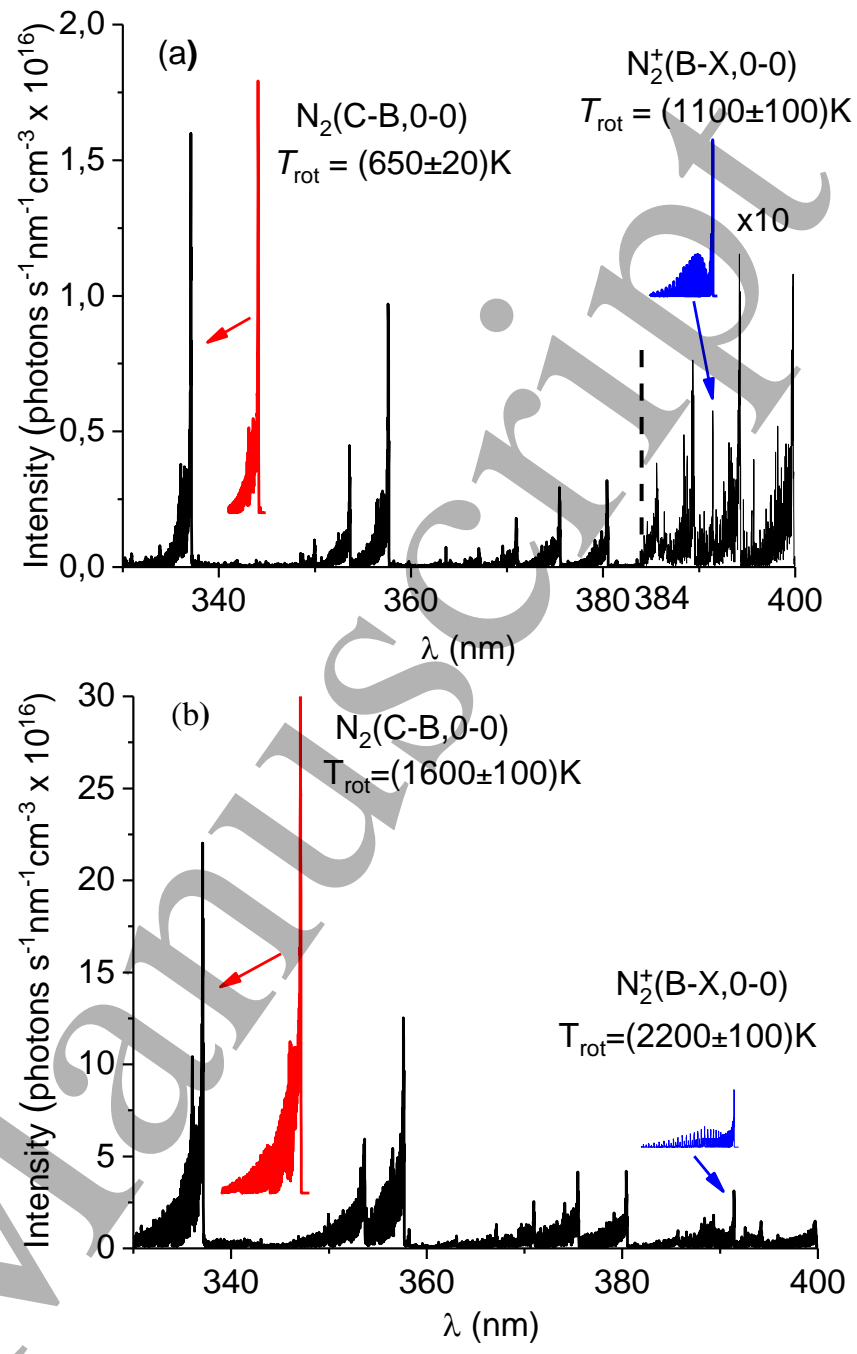

Figure 2. Emission spectra of nitrogen MW plasma for (a) low $\left(P_{\text {abs }}\right.$ $=12 \mathrm{~W})$ and $(\mathrm{b})$ high $\left(P_{\mathrm{abs}}=78 \mathrm{~W}\right)$ absorbed power. The $\mathrm{N}_{2}(\mathrm{C}-\mathrm{B}, 0-$ $0)$ (red) and $\mathrm{N}_{2}{ }^{+}(\mathrm{B}-\mathrm{X}, 0-0)$ (blue) vibrational bands are simulated and fitted to the measured ones (see text). In spectrum (a) intensity in spectral range $\lambda>384 \mathrm{~nm}$ (from the vertical dashed line to the right) is multiplied by 10 . The simulated spectra are shifted for clarity and their mesured counterparts are pointed by arrows

By using the measured intensities of the nitrogen emission lines, the determined plasma volume, the nitrogen density and the calculated rate constants for electron impact excitation, we determine the averaged reduced electric field and the electron density in the active region of the MW resonator by applying the Eq. (9-18) and Eq. (10-19), respectively. The determined plasma parameters are listed in Table 1.

Table 1. Results of the MW plasma characterization

\begin{tabular}{|c|c|c|c|c|}
\hline $\begin{array}{c}P_{a b s} \\
(\mathrm{~W})\end{array}$ & $\begin{array}{c}T_{g} \\
(\mathrm{~K})\end{array}$ & $\begin{array}{c}E / N \\
(\mathrm{Td})\end{array}$ & $\begin{array}{c}E \\
(\mathrm{kV} / \mathrm{m})\end{array}$ & $\begin{array}{c}n_{e} \\
\left(\mathrm{~m}^{-3}\right)\end{array}$ \\
\hline 12 & $650 \pm 20$ & $56 \pm 1.5$ & 6.6 & $(6.4 \pm 2.7) \times 10^{18}$ \\
\hline 78 & $1600 \pm 100$ & $66 \pm 2.5$ & 3.1 & $(3.5 \pm 1.7) \times 10^{19}$ \\
\hline
\end{tabular}




$$
\begin{gathered}
\frac{\left(I_{N_{2}(C)}\right)^{2} Q_{N_{2}^{+}(B)}}{I_{N_{2}^{+}(B)} Q_{N_{2}(C)}^{2}\left[N_{2}\right]^{2}} \\
=\frac{\left(k_{N_{2}(C)}^{N_{2}(X)}+k_{N_{2}(A)}^{N_{2}(X)} \cdot \frac{\mathrm{B} 1 \cdot \mathrm{B} 2 k_{N_{2}(C)}^{N_{2}(A)}}{k_{N_{2}(B)}^{N_{2}(A)}+k_{N_{2}(C)}^{N_{2}(A)}+k_{i o n}^{N_{2}(A)}+k_{d i s s}^{N_{2}(A)}}\right)^{2}}{k_{N_{2}^{+}(B)}^{N_{2}^{+}(X)}} \\
=\frac{\left(k_{N_{2}(C)}^{e x c}\right)^{2}}{k_{N_{2}^{+}(B)}^{N^{+}(B)}}=f\left(\frac{E}{N}\right) \\
n_{e}=\frac{I_{N_{2}(C)}}{Q_{N_{2}(C) \cdot\left[N_{2}\right] \cdot k_{N_{2}(C)}^{e x C}}} \cdot
\end{gathered}
$$

To estimate the accuracy of measured plasma parameters the contribution of different processes and their cross sections in Eqs. (18) and (19) are analysed. The contributions of direct electron impact excitation of $\mathrm{N}_{2}(\mathrm{C})$ to the $\mathrm{N}_{2}(\mathrm{C}-\mathrm{B}, 0-0)$ emission (first term in Eq. (18) - $k_{N_{2}(C)}^{N_{2}(X)}$ ) and the $\mathrm{N}_{2}(\mathrm{C})$ excitation via $\mathrm{N}_{2}$ (A) (second term in Eq. 9) for $12 \mathrm{~W}$ and 78 $\mathrm{W}$ discharge powers are $48 \%$ and $40 \%$, respectively. These values are used to weight the relative error contributions of direct electron impact excitation (first term in Eq. (18)) and the stepwise excitation via $\mathrm{N}_{2}(\mathrm{~A})$ (second term in Eq. (18)) of $\mathrm{N}_{2}$ (C) state to the estimated error bars of plasma parameters. Further, accuracies of cross sections for the relevant processes are taken from the literature and used for the error estimation. Measured cross sections of processes (1), (3) and (4) and their accuracies are analysed in $[11,13]$. The accuracies of cross sections for stepwise excitation of $\mathrm{N}_{2}(\mathrm{C})$ state via nitrogen metastable $\mathrm{N}_{2}$ (A) (Eqs. (4) and (5)) are estimated by analysing of measured [11] and calculated [12] cross sections. In addition, we estimated the accuracy of solving the non-linear equation (18). The estimated error bars are listed in Table 1.

As is previously assumed, in our analysis of measured data we neglect direct impact excitation of $\mathrm{N}_{2}^{+}(\mathrm{B})$ state. To validate this assumption, we determine the relative contribution of direct electron impact excitation of $\mathrm{N}_{2}{ }^{+}(\mathrm{B})$ state (Eq. B) to $2.7 \times 10^{-5}$ and $2.3 \times 10^{-5}$ at $12 \mathrm{~W}$ and $78 \mathrm{~W}$, respectively. Based on this values we can conclude that influence of direct electron excitation to the $\mathrm{N}_{2}{ }^{+}(\mathrm{B}-\mathrm{X})$ emission is negligible in our experiment.

The radial images of the discharge are presented in Fig.3. In the case of the low power (Fig. 3a) the plasma emission is concentrated closely to the quartz glass and symmetrically to the position of the resonator gap capacitance. The image of high MW power (Fig. 3b) presents a coaxial plasma layer with a minimum of light emission intensity near the tube axis. By using the FWHM of the radial intensity distribution, the estimated radial thicknesses of the plasma layer at low and high powers are $0.75 \mathrm{~mm}$ and $1.2 \mathrm{~mm}$, respectively. The plasma layer thickness helps us to determine the plasma volume at different absorbed powers.
The both images show that the plasma emission and the plasma density are not homogeneously distributed over the discharge cross-section. The low power discharge has a very narrow emission area close to the quartz wall and symmetrically arranged in respect to the axis of the gap capacitor. This strongly indicates the plasma E - mode of an ICP, where the plasma density is lower and the sheath voltage is higher. This corroborates well with the position of the maximum intensities near the gap capacitor, where the electric field is the strongest. Recently developed model in our group shows that the strongest electric field in the E-mode is close to the gap capacitor. Nevertheless, due to the plasma shape and relatively high plasma density $\left(6.4 \times 10^{18} \mathrm{~m}^{-3}\right)$ we believe that this mode is not a pure E-mode but more hybrid mode $(\mathrm{E} / \mathrm{H})$, which was previously described for radio-frequency plasmas [19].

For the high absorbed power $(78 \mathrm{~W})$ the plasma takes the "donuts" shape. The ring of high intensity plasma emission is close to the quartz wall with the small deviation of the radial symmetry close to the gap capacitor. Nevertheless, the high electron density $\left(3.5 \times 10^{19} \mathrm{~m}^{-3}\right)$ and the high gas temperature $(1600 \mathrm{~K})$ strongly indicate the H-mode of ICP MMW plasma source.

We have to note that, by increasing the incident power for given pressure and reactor radius there is a limitation at 158 W. By further increase, the plasma cannot support the H-mode and switch to the E-mode or the hybrid mode. The reason for this behavior is still not clearly understood and needs further experimental and theoretical studies.

As it is mentioned above, the MW plasma is characterized under the assumption of the negligible influence of diffusion on the steady state density of nitrogen metastables $\left(\mathrm{N}_{2}(\mathrm{~A})\right)$. To estimate this we assume the opposite: extremely fast diffusion of nitrogen metastables and consequently negligible low efficiency of stepwise excitation of $\mathrm{N}_{2}(\mathrm{C}-\mathrm{B})$ light emission (see Eq. (1)). The reduced electric field, determined in this extreme case, is on average $10 \%$ higher than that presented in Table 1 and the electron density 30\% lower. Therefore, we conclude that the influence of the metastable diffusion on the reliability of the determined plasma parameters of MMW reactor is insignificant and is beyond of the present study.

The novel ICP coupled MMW plasma source operated in nitrogen flow at $1000 \mathrm{~Pa}$ is characterized by optical spectroscopy and optical imaging. The absolute intensities of the second positive and the first negative emission systems of molecular nitrogen are measured. The careful analysis of the rotational distributions of $\mathrm{N}_{2}(\mathrm{C}-\mathrm{B}, 0-0)$ and of $\mathrm{N}_{2}{ }^{+}(\mathrm{B}-\mathrm{X}, 0-0)$ vibrational bands helps to rule out the stepwise excitation as the dominate excitation mechanism for the $\mathrm{N}_{2}{ }^{+}(\mathrm{B}-\mathrm{X})$ state. The absolute intensity measurements reveal the high electron density $\left(3.5 \times 10^{19} \mathrm{~m}^{-3}\right)$ and high gas temperature $(1600 \mathrm{~K})$ comparable to the electron densities of atmospheric pressure plasma torches [20]. The possibility of making arrays of MW ICP plasma sources has a large potential for industrial 
applications. Nevertheless, there are several opened questions that will be address in the future. Some of them are the $\mathrm{H}$ - to E-mode transition and the limitations in the maximum absorbed power.
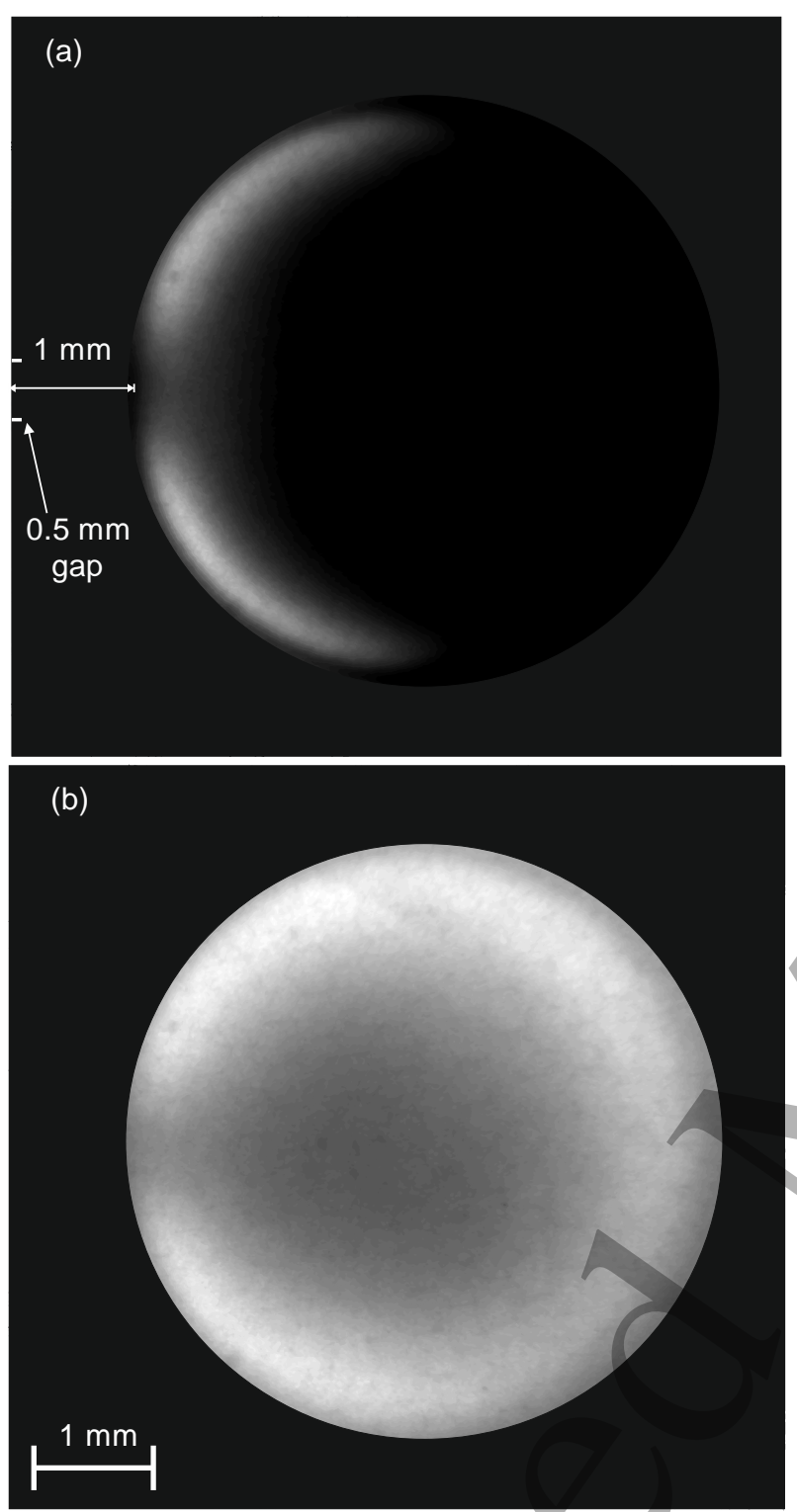

Figure 3. Radial images of the MW plasma: (a) hybrid E/H mode, absorbed power $P_{\text {abs }}=12 \mathrm{~W}$ and (b) $\mathrm{H}$ - mode, $P_{\text {abs }}=78 \mathrm{~W}$. Two horisontal bars on (a) indicate the approximate position of the $0.5 \mathrm{~mm}$ gap capacitor, situated closely to the outer quartz tube wall, e.g. 1 $\mathrm{mm}$ away from the plasma to the left. Light reflection by the tube wall is suppressed. The exposure time is $20 \mathrm{~ms}$ (a) and $5 \mathrm{~ms}$ (b).

\section{Acknowledgements}

This project is supported by DFG, project No. 38909373 .

\section{ORCID iDs}

Ilija Stefanović https://orcid.org/0000-0002-1652-1287

\section{References}

[1] Schulz U, Munzert P, Kaiser N 2001 Surface and Coatings Technology 142 -144 507

[2] Tatarova E, Bundaleska N, Dias F M, Tsyganov D, Saavedra R and Ferreira C M 2013 Plasma Sources Sci. Technol. 22065001

[3] Al-Shamma'a A I, Wylie S R, Lucas J and Pau C F $2001 \mathrm{~J}$. Phys. D: Appl. Phys. 342734

[4] Giersza J, Jankowskia K, Ramszab A and Reszkec E 2018 Spectrochimica Acta Part B: Atomic Spectroscopy 14751

[5] Porteanu H E, Gesche R and Wandel K 2013 Plasma Sources Sci. Technol. 22035016

[6] Piasecki W and Froncisz W 1993 Meas. Sci. Technol. 41363

[7] Bibinov N, Halfmann H, Awakowicz P and Wiesemann K, 2007, Meas.Sci.Technol. 18, 1327

[8] Steves S, Styrnoll T, Mitschker F, Bienholz S, Bibinov N and Awakowicz P 2013, J. Phys. D: Appl. Phys. 46, 445201

[9] Pothiraja R, Ruhrmann C, Engelhardt M, Bibinov N and Awakowicz P 2013 J.Phys.D:Appl.Phys, 46, 464012

[10] Offerhaus B, Lackmann J W, Kogelheide F, Bracht V, Smith R, Bibinov N, Stapelmann K and Awakowicz P 2017 Plasma Proc.Polymer, 14, 1600255

[11] Itikawa Y 2006 J. Phys. Chem. Ref. Data 35 31-53

[12] Bacri and Medani A 1982 Physica C 112101

[13] Crandall D H, Kauppila W E, Phaneuf R A, Taylor P O and Dunn G H 1974 Phys. Rev. A 92545

[14] Laux C O and Kruger C H 1992 J. Quant. Spectrosc. Radiat.Transfer $\mathbf{4 8} 9$

[15] Valk F, Aints M, Paris P, Plank T, Maksimov J and Tamm A 2010, J. Phyics D: Appl. Phys. $\mathbf{4 3} 385202$

[16] Dyatko N A, Kochetov I V, Napartovich A P and Sukharev A G 2011 EEDF: The software package for calculations of the electron energy distribution function in gas mixtures State Science Center Troitsk Institute for Innovation and Fusion Research (142190, Troitsk, Russia) laxcat.net/software/EEDF/

[17] Bibinov N, Dudek D, Awakowicz P and Engemann J 2007 J. Phys. D: Appl. Phys. 40, 7372

[18] Rajasekaran P, Ruhrmann C, Bibinov N and Awakowicz P 2011 J. Phys. D: Appl. Phys. 44, 485205

[19] Wegner Th, Küllig C and Meichsner J 2017 Plasma Sources Sci. Technol. 260250006

[20] Baeva M, Hemplel F, Baierl H, Trautvetter T, Foest R and Loffthagen D 2018 J. Phys. D: Appl. Phys. 51, 385202 